\title{
Cardiovascular Sonothrombolysis - Therapeutic Application of Ultrasound
}

\author{
Luciene Ferreira Azevedo ${ }^{2}$, Thomas R Porter ${ }^{1}$, Jose Antonio F Ramires ${ }^{2}$ and Wilson Mathias Jr ${ }^{2 *}$ \\ ${ }^{1}$ Department of Internal Medicine, Division of Cardiovascular Medicine, Brazil \\ ${ }^{2}$ Department of Cardiopneumology, Instituto do Coração (InCor), Sao Paulo - State of Sao Paulo, Brazil
}

*Corresponding author: Wilson Mathias Jr, MD, University of Sao Paulo Medical School, Department of Cardiopneumology, Instituto do Coração (InCor), Brazil

\section{ARTICLE INFO}

Received: 㗀 September 13, 2019

Published: 陆 September 18, 2019

Citation: LucieneFerreiraAzevedo, Thomas R Porter, Jose Antonio F Ramires, Wilson Mathias Jr. Cardiovascular Sonothrombolysis - Therapeutic Application of Ultrasound. Biomed J Sci \& Tech Res 21(3)-2019. BJSTR. MS.ID.003600.

Keywords: Perfluorocarbons; Microbubble; Ultrasound; Myocardial Infarction

Abbreviations: US: Ultrasound; AMI: Acute Myocardial Infarction; IC: Inertial Cavitation; STEMI: ST Segment Elevation Myocardial Infarction; PCI: Percutaneous Coronary Intervention; MI: Mechanical Index
ABSTRACT

Purpose: This review will provide the biomechanical effects of ultrasound (US) alone and associated with microbubbles, their potential therapeutic mechanisms, and recent pre-clinical and initial clinical trials exploring the efficacy of sonothrombolysis as an adjunct to current emergent therapies in acute coronary syndromes. Furthermore, we discuss the specific characteristic of US technique applied in different studies conducted in humans and Acute Myocardial Infarction (AMI).

Findings: US has gained widespread use in diagnostic cardiovascular applications and as treatment of peripheral disease and coronary disease. First used directly in vitro studies, it was used as catheter-delivered device for US angioplasty and lately applied externally as transcutaneous and transthoracic device. After adjusts in amplitudes and frequencies US applied for treatment of thrombosed vessels presents very similar characteristics typical of diagnostic use and its biomechanical effects on tissue are of extensive utility. High-intensity and low-frequency focused US is one therapeutic US modality which have been investigated for treating ischemic peripheral and ischemic heart disease. In addition, diagnostic US pressures have the ability to induce Inertial Cavitation (IC) of systemically administered microbubbles and this method seems to be effective in restoring coronary vascular and microvascular flow in acute ST Segment Elevation Myocardial Infarction (STEMI). Moreover, microvascular flow appears to improve even if upstream large vessel flow has not been achieved. The initial clinical trials examining the efficacy of short pulse duration US high-MI impulses in patients with STEMI have demonstrated that there is improved patency of the infarct vessel, and improved microvascular flow following percutaneous coronary intervention.

Conclusion: sonothrombolysis has potential for improving early epicardial patency and reduce Left Ventricular remodeling with added to current interventional strategies in STEMI. Ultrasound - peripheral and cardiac therapeutic applications.

\section{Introduction}

US energy has been used for almost 3 decades in interventional medicine. Formerly considered only for diagnosis, it has been lately used as promising therapeutic method. In diagnostic field, the US ability was enhanced with the combination of US contrast agents, which improves image delineation of organs, including chambers of the heart, assists in imaging blood flow, including blood flow deficiencies (organ perfusion); and also can be applied for the evaluation of patency of anatomical structures (e.g. fallopian tubes). As therapeutic method, US has been used alone or as adjuvant to facilitate artery angioplasty. Lately, its efficacy as treatment of thrombosed arteries in AMI has been demonstrated both in percutaneous transluminal and in transtoracic applications. Its action is mainly through IC of systemically administered US contrast agents and this mechanism will be also discussed in this review. 
Despite the effectiveness of previous treatments for peripheral or coronary thromboembolism namely direct surgical embolectomy and/or arterial bypass, percutaneous balloon catheter extraction, and local or systemic fibrinolytic therapy, side effects and complications cannot be discharge. Several studies demonstrated increased risk for operative morbidity, bleeding complications secondary to fibrinolytic therapy, arterial perforation, intimal injury, avulsion of atherosclerotic plaque, arteriovenous fistulas, impaction of an embolus or thrombus into the distal arterial tree, or shifting of the thrombus [1-3] In this context, US appears as a method with minimal chance of undesired events. The new concept of blood vessel thrombi dissolution by US was initially described by Trubestein et al. [4,5] and was latter demonstrated in vitro,[6-9] in vivo and in animal [7-10] and human studies [11-14].

In the previous classical studies, the authors demonstrated the potential of US for destroying artificial thrombi in peripheral blood vessels of dogs and a 2-day-old thrombosis of the femoral artery of one patient.4,5 Following their studies, many others showed in vitro and in vivo peripheral blood clot disruption with this technique. Hong et al.6 demonstrated the effectiveness of US to disrupt in vitro human blood clot of 1 to 7 days with comparable efficacy, despite age. Ariani et al. [7] demonstrated the efficacy and safety of catheter-delivered pulsed-wave US through high rates of in vitro human whole blood clot disruption and in vivo canine femoral artery thrombus dissolution after produced acute thrombosis. The successful recanalizations were confirmed by angiography with histological studies showing no evidence of thermal or cavitation injury, occlusive distal embolization or perforation. Successful recanalization was also observed in vivo occluded canine femoral arteries [8] using an experimental ultrasonic angioplasty device, with a reduction of the obstruction from $93 \%$ to $18 \%$ without arterial wall injury. In addition, these authors demonstrated that sonication was also effective to reduce the size of atherosclerotic plaques (in vitro aortic segments) without damage to the media or adventitia, demonstrating the potential of US for angioplasty. More than 1 decade later, the effectiveness of percutaneous catheterdelivery US was demonstrated in clinical studies of vascular disease without evidence of clinical complications, such as arterial emboli, dissection, spasm, or perforation $[15,16]$. In addition, Siegel et al. [10] observed the opening of completely obstructed xenograft implantation of atherosclerotic human vessels in 12 dog arteries (carotid, aortic, iliac and femoral) by applying US energy through a catheter-delivery system creating an appropriated lumen for subsequent balloon dilation. Further, they found that calcific arterial obstructions do not impede US recanalization. In the vessels with xenograft implant, there was no angiographic evidence of US-induced vasospasm, thrombosis or arterial dissection. In other study, Siegel et al. [17] demonstrated, in patients undergoing percutaneous US angioplasty, $86 \%$ of recanalization in arterial lesions including 34\% with calcification. These authors observed decrease in the stenosis from $94 \%$ to $55 \%$ after US angioplasty and to $12 \%$ after balloon angioplasty and restenosis rate was of only $20 \%$ at 6 to 12 months follow-up.

The studies were not only limited to the potential use of US in peripheral vessels but also conducted as an angioplasty and clot-dissolving device in thrombosed coronary arteries. This technique differs from balloon angioplasty, as it has been shown to provoke dissolution of calcific and fibrotic atherosclerotic plaques, thrombus and arterial vasodilatation. Steffen et al.9 showed that catheter-delivered US dissolved blood clots in vitro and in vivo dog coronary arteries. Angiography revealed widely patent coronary arteries in $87 \%$ of the dogs and there was no histologic evidence of US-mediated vessel damage. In the following year, the results of The European Multicenter Experience with therapeutic US coronary angioplasty in symptomatic patients were reported [18]. US reduced the mean arterial stenosis from 86 to $71 \%$ in 136 of 163 patients who presented lesions with calcification or thrombus. Siegel et al. [19] demonstrated, in the clinical part of their study, in patients, that catheter-delivered high-intensity, low-frequency US (intracoronary US) decreased the coronary arterial stenosis from $80 \%$ to $60 \%$ after US and to $26 \%$ after adjunctive balloon angioplasty. Using postmortem occluded coronary, they showed $100 \%$ recanalization and very small particulate debris $(99 \%$ were lower than 10 microns in diameter). These previous studies confirmed the usefulness of US to dissolve thrombi, increase arterial distensibility and modify atherosclerotic plaques without adverse reaction or with only small damage to US exposure.

The results of percutaneous US thrombolysis were also positive in human studies of AMI as reperfusion therapy [11,14,20,21]. Hamm et al. [14] reported a case of successful US-mediated intracoronary thrombus dissolution in a patient with AMI. The same group21 treated 11 patients with US and observed removing of angiographically visible clots. TIMI flow 3 and 2 were observed in $64 \%$ of patients and after adjunctive percutaneous transluminal coronary angioplasty, TIMI 3 flow was present in 91\% of the patients. Two years later, the researchers 20 tested the effect of intracoronary US thrombolysis as initial therapy in patients with AMI. US was effective and safe to recanalize thrombotically occluded coronary arteries. Angiographically visible thrombi were dissolved without US related morbidity or adverse effects. Rosenschein et al. [11] corroborated the clinical feasibility of percutaneous transluminal coronary US thrombolysis in $15 \mathrm{AMI}$ patients, demonstrating successful reperfusion (TIMI grade 3 flow) in $87 \%$ of the patients without adverse angiographic signs or clinical effects during procedure.

All these results together suggest US as an effective and safe treatment for peripheral and coronary arterial thrombosis since its efficacy to dissolve tissues with low elasticity, such as atheroma and thrombi, was demonstrated. Of note, the US application technique progressed in order to prevent possible damage to normal tissues near the sites of occlusions, beginning with direct in vitro application, delivered through catheters within the vessels 
and ultimately, with transcutaneous or transthoracic application, as described hereafter in this review.

\section{Ultrasound Associated with Fibrinolytic Therapy}

Thrombolytic therapy presents several limitations, such as, low rate of TIMI grade 3 reflow in AMI patients, intermittent patency and reocclusion of recanalized artery or clinical complications, such as cerebral and gastrointestinal bleeding. In an attempt to overcome these limitations, to shorten occlusion time of arteries, and to reduce the total dose of thrombolytic agents, a number of researchers have reported acceleration of thrombolysis by US energy application in association with fibrinolytic agents [22-24] Kudo25 published the first studies describing the use of US to increase the efficacy of systemic tissue-type plasminogen activator (t-PA). He observed that transcutaneous continuous mode US enhanced t-PA-induced fibrinolysis in a canine model of femoral arterial thrombi and was associated with an $80 \%$ decrease in the time required for recanalization. Tachibana [22] investigated this effect on artificial thrombus in vitro and revealed the US boosting of the fibrinolytic effect of urokinase, a t-PA. US accelerated the fibrinolysis by more than fourfold in the early stage of lysis and urokinase concentration could be reduced to approximately onetenth of the original dose to achieve equal fibrinolysis effect.

Lauer et al. [23] also demonstrated in whole human clots in vitro the efficacy of intermittent US for increasing lysis when associated with t-PA. Intermittent US also showed a trend toward enhancement of t-PA-induced clot lysis in a rabbit jugular vein thrombosis model without provoking thermal changes or tissue damage. The potential of external pulsed US to enhance in vitro thrombolysis of human blood thrombi when using urokinase or streptokinase was also tested by Luo et al. [24] and the authors observed increased lysis with higher US power output with any of the lytic agents. The extent of lysis was higher with longer US exposure time and with fresh thrombi. Importantly, lower doses of the lytic agents combined with US had the same lysis efficacy to that of higher dose used alone, reducing the potential bleeding complications associated with higher doses of lytic agents. In addition, this combination shortened the rate of thrombolysis time by $50 \%$ which could promote early recanalization in acute thrombotic states.

Despite different characteristics of US technique applied, these above data suggest that non-invasive intermittent US acts as an adjunct to thrombolytic therapy enhancing both efficacy and rate of thrombolysis. It seems that US enhance the efficacy of some drugs to produce lysis through perturbation of the clot thereby allowing increased binding of the thrombolytic agent to fibrin. This hypothesis is based on mechanical effect of US: cavitation, which can generate high-velocity jets or a steady flow of fluid known as microstreaming. In addition, countless microscopic bubbles that oscillate in size near the thrombus during US exposure, may influence the local fluid flow and, therefore, enhance transport and penetration of endogenous or exogenous lytic agents into the thrombus and thus accelerate fibrinolysis $[26,27]$.

\section{Mechanism of Ultrasound and Ultrasound Associated with Microbubbles as Therapy}

US has been generally used for diagnostic imaging using $\mathrm{MHz}$ frequencies. As a therapeutic tool, it was developed to direct mechanical energy effects of low-frequency $(\mathrm{kHz})$ by virtue of its ability to exert mechanical forces, stresses, and torques, as well as displacements and flow. Low-frequency US energy accelerates thrombolysis by itself or when used in conjunction with a thrombolytic agent in vitro and in vivo or when adding US contrast agents. Basically, mechanical effects induced by lowfrequency US, such as, cavitation, precavitation which leads to microstreaming and radiation force [6,8,9,23,28-35] are the main mechanisms to explain thrombi and atherosclerotic plaques disruption. Cavitation is a phenomenon by which small gas filled cavities, called microbubbles, exposed to an ultrasonic field grow, oscillate, collapse and disrupt, exerting various physical stresses in a liquid medium, resulting in tissue alteration. Both the vibration of microbubbles and their rapid collapse in the acoustic field result in local pressures of up to $20000 \mathrm{~atm}$ [36].

This mechanical shock of bubble collapse is felt at a distance of a few microns, resulting in intense shear stress that could break fibrin bonds of thrombi and induce thrombus fragmentation. Acoustic cavitation is presented in two forms:

1. Non-inertial - described as the stable oscillation of gasfilled bodies in an ultrasonic field, without compromise its integrity, which causes solution microstreaming and produces high shear stresses in the surround medium. Human bioeffects due to stable cavitation are likely through exogenous administration of microbubbles (US contrast agents); and

2. Inertial (unstable or collapsing cavitation) - resulting from the gas-filled cavity expansion during part of the acoustic cycle and its rapid and violent collapse because of erratic oscillations and rapid growth of the cavity. This collapse produces high temperatures and pressures with important practical consequences such as light emission and the formation of reactive chemical species. Bubble oscillation also produces mechanical effects caused by the viscous surrounding fluid, which opposes the oscillation, creating what is known as radiation force $[16,37,38]$.

Chen et al. [38] using ultra-high-speed imaging documented the inertial cavitation of a microbubble interacting with a thrombus surface, with demonstration of the translational motion of microbubbles toward the thrombus and the possible role that Bjerknes forces may play in sonothrombolysis. In fact, Hong et al. [6] suggested mechanical and cavitational energies as mechanisms to explain ultrasonic clot disintegration instead of biochemical activation of the fibrinolytic cascade. This hypothesis was based on the fact that US alone produces eight- to 16 -fold fewer D-dimers 
than in streptokinase-exposed samples, indicating the lack of fibrinolytic activation by the wire probe. Besides the demonstration that cavitation effect plays an important role in the mechanism of US thrombolysis, Rosenschein et al. [29] also showed that tissues presenting low levels of elasticity, as thrombi, are highly sensitive to US ablation. In contrast, tissues containing a heavy matrix of collagen and elastin, such as arterial wall, bladder, or heart valves, are resistant to US.

The microbubbles cavitation produced by US seems to have not only an effect on thrombi dissolution. This phenomenon causes intravascular shear stress in regions near the microbubbles39 and could elicit NO release which in turn would contribute to the improvement of microvascular perfusion. Direct applied lowfrequency US improved the myocardial tissue perfusion in an animal model of fixed coronary occlusion and this effect was abolished after administration of NO synthase inhibitor [40]. In addition, Belcik et al. [41] demonstrated that US with microbubbles increased the hindlimb muscle blood flow, femoral artery dilatation and reversed tissue ischemia in mice and that the inhibition of Endothelial Nitric Oxide Synthase (eNOS) attenuated flow augmentation by $70 \%$. These findings point to the cavitation-related increase in shear stress and the important role of the biologic mediators, eNOS and NO.

New possible candidate to explain the mechanisms involved in the improvement of myocardial perfusion and LV contractile function in patients with large AMI is been tested by Leone et al. [42] in the RIGENERA 2.0 trial. In this regards, the administration of recombinant human granulocyte-colony stimulating factor (G-CSF), which causes bone marrow-derived stem cell mobilization, which in turn contribute to cardiac repair after acute myocardial injury, $[43,44]$ is associated with an improvement in LV ejection fraction. Thus, it was hypothesized that the association of myocardial contrast echocardiography could enhance the bone marrowderived cells homing in the myocardium and determines superior improvement in regional and global contractile function, myocardial perfusion and infarct extension in patients with large ST-Segment Elevation Myocardial Infarction (STEMI). This phenomena has already been observed by these authors (unpublished data) [42] and demonstrated in animal studies [45,46] and is still under investigation.

Interesting to know that improvement in microvascular blood flow could even occur in the absence of epicardial recanalization and US-induced coronary artery vasodilatation is a possible explanation for this finding. Low-frequency US applied alone resulted in vasodilation in canine coronary artery (transthoracic) [47] and human brachial arteries (transcutaneous) [48] It has been showed that acute arterial thrombi still have small microchannels that cannot be seen with angiography, but which permit microbubbles to penetrate the interior of a thrombus [39] Thus, an increase in coronary diameter induced by US could improve local delivery of both microbubbles and/or lytic agent through micro-channels, resulting in increased flow in the downstream microvasculature, even without angiographic evidence of coronary artery reperfusion.

\section{Ultrasound Associated with Pharmacological Agents - Microbubbles Echocardiography Contrast}

Once microbubbles are naturally present in a liquid medium or can be spontaneously formed or be exogenously injected in the blood streaming; the acoustic cavitation process displayed by US become one important non-invasive method in clinical practice for diagnostic purpose and therapeutic purpose, such as thrombolysis $[26,30]$. In this regard, various transpulmonary echo contrast agents, which are basically microbubbles, such as gas-filled microspheres, albumin microbubble or Lipid-Encapsulated Perfluorocarbons (LEP) like Definity (Lantheus Medical) or Sonazoid (GE Healthcare) have been developed and used by intravenous injection associated with US. Microbubbles can decrease the threshold intensity of US needed to induce cavitation, as well as act as generators of microstreaming (rapid fluid movement). It has been also important to assess tissue blood flow at the microvascular level. In the assessment of tissue perfusion, US imaging become more accurate, detecting harmonics or overtones produced by microbubbles, and enhance microbubbles signal [49]. The methods for quantifying tissue blood flow consider the similar behaviour of microbubbles in the circulation as compared with that of the red blood cells [50] and the fact that microbubbles can be destroyed at high acoustic powers. Briefly, the method calculate microvascular perfusion from the product of microvascular red blood cell velocity, measured by the rate of increase in acoustic signal (rate of replenishment) after microbubbles destruction by high power US, and microvascular blood volume, estimated from acoustic intensity from microbubbles, or amount of contrast enhancement $[49,51]$ Myocardial contrast US is mainly helpful to diagnose AMI and to detect coronary artery disease [52] and provides information on perfusion at capillary level.

The first air-filled microbubbles, using agitated saline solution, produced bright eco enhancement of the blood, despite the very low stability and short duration [53] The action of microbubbles as US contrast is based on their acoustic wave scattering. When a pulse of US excited a gas microbubble, with a diameter as low as several microns, the bubble oscillates compressing and expanding during high- and low-pressure phases, respectively and emitting secondary US waves of high intensity in all directions. This high reflectance of microbubbles provides bright blood pool contrast from vessels or cardiac chambers. Thus, gas bubbles generate a backscatter signal which is stronger by several orders of magnitude, justifying the use of gas as the core of the US contrast materials [54] The next challenging was to cover the gas core with a shell polymer- based, [55] protein-based, [56] or lipid-based surfactant [57] which would increase the lasting of the gas bubble. Thus, the first generation of 
US contrast agents (air-filled, shell-coated microbubbles) with extended storage stability and standardization of size was created.

The encapsulation process provided microbubbles size standardization and increased their stability, becoming possible intravenous application. The first encapsulated microbubble agent (Albunex) was formed by sonication of 5\% human serum albumin and was approved for human use by the US FDA in 1994.49 One year later, Tachibana \& Tachibana [26] tested the potential of these albumin air-filled microbubbles to lower the threshold of US induced acoustic cavitation and accelerate thrombolysis in vitro when associated or not with urokinase. In fact, albumin microbubbles induced further acceleration of thrombolysis by US energy. Although the air-filled encapsulated microbubbles provide transpulmonary passage they were not very stable and were destroyed by losing gas during transit to the systemic circulation following intravenous injection, resulting in a decrease in contrast enhancement [58].

The production of microbubbles contrast agents must consider many factors that has influence on their signal and action, such as compressibility and density of the gas, viscosity and density of the surrounding medium, frequency and power of US applied, bubble size, viscous and elastic damping effects of a shell and the capability of destruction of microbubbles [49,59-62]. The later feature is important for both perfusion imaging protocols and for therapeutic applications [49]. Therefore, an alternative to improve the stability of preformed microbubbles was the modification of the microbubble shell and/or gas content. Authors suggested the development of microbubbles with optimal shell viscoelastic properties to provide better signal-to-noise with low-MI imaging [62]. The application of organic gases, as fluorocarbons and sulphur hexafluoride, which are poorly soluble in biological fluids, presented enhanced stability in vivo. Encapsulation of high-molecularmass gases with lipids, proteins or biopolymers is still used to control their size distribution, and to further improve stability by reducing diffusion and surface tension. The second generation of commercial microbubbles-based US contrast agents is generally filled with perfluorocarbon gas, which present increased lifespan in vivo and provides enough time to acquire heart and peripheral organs images [63]. Porter et al. [30] demonstrated the potential of the US contrast agent perfluorocarbon-exposed sonicated dextrose albumin microbubbles to enhance the thrombolysis effectiveness of low-frequency US in vitro and to provide a reduction in the dosage of thrombolytic agents for treating thrombosis.

Of note is that different types of microbubbles can present different responses on lysis. In this regard, Mizushige et al. [64] studied 3 different gaseous microbubbles (sonicated 5\% albumin microbubbles, $\varnothing$ 3-5 $\mu$ m; SH-U508A, $\varnothing ~ 2-4 \mu \mathrm{m}$ and DDFP emulsion - 2\% dodecafluoropentane, $\varnothing 3-8 \mu \mathrm{m}$ ) and verified their effect on accelerating in vitro thrombolysis by US and tPA (Tisokinase). Weight reduction of the thrombus was greatest in the DDFP Group. This group also presented the longest persistence of the microbubbles and greatest change in multiple cavity formation, observed histopathologically. Interestingly, the efficacy of DDFP without thrombolytic agents was previous described and the authors [65] demonstrated that 2\% DDFP emulsion in combination with transcutaneous US recanalized angiographically $73 \%$ of rabbit thrombosed iliofemoral arteries (TIMI grade II or III flow). This study shows that DDFP, a second generation US contrast agent, can enhance the clot-disruption effect of transcutaneous US in both in vitro and in vivo experiments.

For clinic use, especially in patients, it is important to have in mind the commercially produced contrast agents. Lindner [49] presents a partial list illustrating different composition strategies for contrast agents. Currently, the American Society of Echocardiography updated its Guideline on Clinical Applications of Ultrasonic Enhancing Agents in Echocardiography [66] and describes 3 commercially available US enhancing agents approved by the United States food and drug administration: Lumason (sulfur hexafluoride lipid-type A microspheres); Definity (perflutren lipid microsphere) and Optison (perflutren protein type-A microspheres). All these microbubbles contain an inert biocompatible high-molecular weight gas, and are encapsulated with a lipid or protein shell and are designed for Left Ventricular (LV) cavity opacification during echocardiography. According to the American Society of Echocardiography Guideline, microbubbles allow to better define the blood pool improving the identification of endocardial borders for assessment of LV systolic function and regional wall motion [66].

In addition, based on significant scientific literature support, its use has been also recommended for myocardial perfusion, to assess tissue blood flow at the microvascular level and coronary blood flow reserve, pediatric and vascular applications, and during stress echocardiography [66-69]. Microbubbles persist exclusively within the intravascular space, and their existence within any myocardial territory denotes the status of microvascular perfusion within that area [70]. Thus, in cardiovascular practice, microbubbles associated with US have been applied to non-invasively detect LV systolic function, coronary artery disease, to diagnose AMI and to differentiate viable myocardium from scar [69,71-73]. Although not yet recommended by the echocardiography guideline, US contrast agents have been infused intravenously with the purpose of treatment of thrombosis as a reperfusion therapy. This strategy has the potential of dissolving thrombi and not only restores epicardial coronary blood flow but importantly cause reperfusion at microcirculatory level. The results related to this therapeutic application show already important clinical outcomes and are presented in the next topic in this review, especially to treat AMI.

\section{Clinical Results for Ultrasound Associated with Microbubbles as Therapeutic Strategy}

AMI is still an important public health problem worldwide and STEMI constitute a high part of the all AMI. In this matter, it 
is highly recommended to find new strategies to lead to a better outcome in patients suffering of heart disease or presenting for the first time a cardiac event. First, intravenous injections or infusions of perfluorocarbon-exposed sonicated dextrose albumin microbubbles were used in patients with AMI and demonstrated to be very effective to show a persistent contrast defect in the infarct zone following restoration of TIMl grade 3 flow in the infarct vessel which identified patients likely to have deterioration in both regional and global systolic functions [74]. After that, the studies evidenced the success of the US contrast agent technique to open vessels in animal models of acutely thrombosed vessels and AMI $[38,39,75]$. More recently, this intervention has been for the first time applied for clinical investigation in human. Mathias et al. [12] showed that transthoracic diagnostic high-Mechanical Index (MI) US associated with microbubbles applied in patients with STEMI before invasive percutaneous coronary intervention (PCI) increased the early recanalization rate of the culprit coronary artery to nearly $60 \%$ and led to a medium term (6 months) lower LV dysfunction when compared with patients who received PCI only.

More specifically, TIMI-flow grade 2 or 3 recanalization on the angiogram after the initial US treatment, prior to PCI was seen in $60 \%$ of the 20 high-MI treated patients, in $10 \%$ of the 10 low-MI treated patients and in $23 \%$ of the 70 patients treated with PCI only. Microvascular obstruction was lower in high-MI + PCI treated patients, translating in higher improvement myocardial perfusion score index. It is important to note that short-pulse duration ( $5 \mu \mathrm{s})$ of the high-MI treatment was more effective than long-pulse duration $(20 \mu \mathrm{s})$ to epicardial recanalization prior to PCI ( $80 \%$ versus $40 \%$ of the patients, respectively), implying in the maintenance of the same software characteristics used for diagnostic imaging and reducing the possibility of unwanted bioeffects related to prolonged microbubbles cavitation [76] These results are extremely important because of the earlier epicardial recanalization and their beneficial effects at the microvascular level.

More recently, the clinical consequence of the lower microvascular obstruction after diagnostic US-guided cavitation of intravenously administered microbubbles during STEMI was reported. First, in animal model, the authors observed beneficial microvascular effects of US plus microbubbles (short-pulse duration) even without epicardial recanalization, which resulted in improvements in function within the risk area.77 The results suggest that US-induced improvements in microvascular flow during STEMI are not dependent on restoration of anterograde flow in the thrombosed coronary artery and are probably the induction of collateral flow by US-mediated destruction of microbubbles. Recently, the same group conducted the first prospective randomized human study examining the effect of high-MI impulses during a microbubble infusion (sonothrombolysis) in STEMI patients treated with PCI.13 The authors observed angiographic recanalization in $48 \%$ of high-MI PCI patients compared with $20 \%$ in PCI only patients. Importantly, infarct size measured by magnetic resonance imaging and $\mathrm{LV}$ ejection fraction increased immediately after PCI, remaining higher at six months in the highMI patients. The clinical application of transthoracic US contrast or sonothrombolysis was recently extended for the first time to treat pulmonary embolism and successful recanalization of thrombotic occlusion in pulmonary artery stent in human was reported [78].

\section{Ultrasound Characteristics}

The description of ultrasonic frequency and its desired bioeffect when used for therapy without microbubbles infusion was well presented by Siegel et al. [35] Basically, the ultrasonic frequency range stretches from around $20 \mathrm{kHz}(0.02 \mathrm{MHz})$ up to many megahertz, varying from about $20 \mathrm{kHz}(0.02 \mathrm{MHz})$ to $3 \mathrm{MHz}$. In the higher (MHz) range spectrum, low power sound (low energy) will be generated and no chemical reactions are induced. Thus, low-power US in the 2-10 MHz range is employed for diagnostic purpose because sound of such low intensity does not cause any permanent chemical changes in the medium through which it passes. On contrary, at the lower frequencies (just above $0.02 \mathrm{MHz}$ ) much higher power can be generated, leading to cavitation in the medium through which it passes, and consequently the potential to cause chemical changes [35].

Thus, the traditional definition of high-power US relies on US frequency range between 0.02 and $0.1 \mathrm{MHz}(20$ and $100 \mathrm{KHz}$ ) and was the range of operation of the majority US generators and was used for treatment of arterial thrombi in recent past. Moreover, the size of microbubbles generated by US during cavitation is inversely proportional to US frequency. Low-frequency US produces large bubbles that in turn produce greater force during their vibration and implosion compared to small bubbles produced at high-frequency US. As US frequency is increased, more power is necessary to produce cavitation [31]. The intensity of the collapsing force is greatly diminished at $>1 \mathrm{MHz}$, and cavitation cannot be produced at all at $>2.5 \mathrm{MHz}$. When higher frequency are used as did in the study of MIZUSHIGE et al. [64] (10-MHz frequency and $1.02 \mathrm{~W} /$ cm2 intensity) compared with others [11,24,34] (45 kHz-1 MHz), smaller change on acoustic pressure will occur and would reduce the US-induced cavitation phenomenon and mechanical damage produced by microbubble streaming will play more important role.

More recently, with the use of microbubbles echocardiography contrast agents, the US frequency range is around 1 to $2 \mathrm{MHz}$ and it is also important consider the combination of the Mechanical Index (MI) that is the power of the US wave. On Table 1 we see some important characteristics of US applied in past and current studies with the purpose of treatment of arterial occlusion and AMI. Additionally, to prevent undesired effects related to thermal and cavitational bio-effects, attention should be given to the temporal average intensities, peak acoustic pressure and related sound frequency, respectively [35,79]. Considering several important factors upon the thrombolytic effect of microbubbles and US, Chen et al. tested the thrombolytic effect of microbubbles 
(perfluorobutane gas lipid-encapsulated) via cavitation, with long the findings that long US tone bursts (up to 5,000 cycles) at high US pulses ( $5 \mathrm{~ms}$ ) exposure at various acoustic pressures $(0.25,0.5$, acoustic pressures enhanced the thrombolytic effect in an in vitro 1.0 and $1.5 \mathrm{MPa})$ and microbubbles concentration $(2 \times 106,2 \times$ flow model [80]. Cavitation detection confirmed continued, albeit 107 and $2 \times 108 \mathrm{MBs} / \mathrm{mL}$ ). This study was conducted motived by diminishing, acoustic activity throughout the 5 ms US excitation.

Table 1: US characteristics in studies of artery occlusion and acute myocardial infarction.

\begin{tabular}{|c|c|c|c|c|c|c|c|c|c|c|}
\hline Study & Model & Lesion location & $\begin{array}{c}\text { Micro } \\
\text { bubbles }\end{array}$ & $\begin{array}{l}\text { US tech- } \\
\text { nique }\end{array}$ & $\begin{array}{l}\text { US probe } \\
\text { Diam- } \\
\text { eter / } \\
\text { lenght }\end{array}$ & $\begin{array}{l}\text { Frequen- } \\
\text { cy }\end{array}$ & $\begin{array}{l}\text { Power } \\
\text { (MI) }\end{array}$ & $\begin{array}{c}\text { Pulse } \\
\text { duration } \\
\text { / Total } \\
\text { time }\end{array}$ & FR & US mode \\
\hline $\begin{array}{c}\text { Siegel RJ } \\
\text { et al. [19] } \\
\text { Circulation } \\
1994\end{array}$ & $\begin{array}{c}\text { In vivo } \\
\text { study:19 } \\
\text { symptomatic } \\
\text { patients with } \\
\text { obstructive } \\
\text { single-vessel } \\
\text { coronary ar- } \\
\text { tery disease }\end{array}$ & $\begin{array}{l}42 \% \text {-proximal } \\
\text { or mid left ante- } \\
\text { rior descending } \\
\text { coronary artery; } \\
58 \% \text {-midportion } \\
\text { of the right coro- } \\
\text { nary artery. }\end{array}$ & & $\begin{array}{l}\text { Cathe- } \\
\text { ter-de- } \\
\text { livered }\end{array}$ & $4.6 \mathrm{~F} /$ & $\begin{array}{l}\text { Low-fre- } \\
\text { quency: } \\
19.5 \mathrm{KHz} \\
(0.195 \\
\mathrm{MHz}) \\
(19.500 \\
\text { cycles / } \\
\text { sec) }\end{array}$ & $\begin{array}{l}16 \text { to } \\
20 W\end{array}$ & & & $\begin{array}{l}\text { 15- second } \\
\text { bursts, with } \\
\text { a } 5 \text {-second } \\
\text { off-time. Pulsed } \\
\text { mode with } 50 \% \\
\text { duty cycle of } 30 \\
\text { milliseconds. }\end{array}$ \\
\hline $\begin{array}{l}\text { Steffen W } \\
\text { et al. [18] } \\
\text { Circulation } \\
\text { Suppl I } \\
1995\end{array}$ & $\begin{array}{l}\text { Calcified and } \\
\text { thrombosed } \\
\text { coronary } \\
\text { lesions }\end{array}$ & $\begin{array}{l}50 \% \text {-left anterior } \\
\text { descending coro- } \\
\text { nary artery; } 20 \% \\
\text { - left circumflex; } \\
\text { 30\%-right coro- } \\
\text { nary artery. }\end{array}$ & & $\begin{array}{l}\text { Ultra- } \\
\text { sound } \\
\text { angio- } \\
\text { plasty }\end{array}$ & $\begin{array}{l}1.2 \mathrm{~mm} \\
\text { or } 1.7 \\
\mathrm{~mm}\end{array}$ & $\begin{array}{c}19.5 \mathrm{KHz} \\
(0.195 \\
\mathrm{MHz})\end{array}$ & & & & \\
\hline $\begin{array}{l}\text { Xie F et al. } \\
\text { [39] JACC } \\
\text { Cardiovasc } \\
\text { Imaging } \\
2009\end{array}$ & $\begin{array}{c}\text { Canine } \\
\text { model OBS: } \\
\text { Intravascular } \\
\text { cavitational } \\
\text { activity was } \\
\text { detected } \\
\text { when an MI } \\
\text { of } 0.5 \text { was } \\
\text { applied. }\end{array}$ & $\begin{array}{l}\text { thrombotic occlu- } \\
\text { sion on femoral } \\
\text { artery }\end{array}$ & MRX-801 & $\begin{array}{l}\text { Diagnos- } \\
\text { ticultra- } \\
\text { sound } \\
\text { system } \\
\text { on phan- } \\
\text { tom }\end{array}$ & $\begin{array}{l}4 \mathrm{C} 1 \\
\text { trans- } \\
\text { ducer }\end{array}$ & $\begin{array}{l}20 \mathrm{MHz} \\
\text { Pulse } \\
\text { repetition } \\
\text { frequency } \\
-5 \mathrm{KHz}\end{array}$ & $\begin{array}{l}\text { 1) Low- } \\
\text { MI }(<0.5 \\
(2.0 \\
\text { MHz) } \\
\\
\text { 2) High- } \\
\text { MI(1.9) } \\
(1.5 \\
\text { MHz) }\end{array}$ & $\begin{array}{c}\text { in vivo } \\
\text { studies: } \\
\text { High-MI } \\
\text { impulses: } \\
\text { (7-cycle } \\
\text { pulse } \\
\text { length) } \\
\text { (5 to } 7 \mathrm{~s} \text { ) } \\
\text { Up to } 45 \\
\text { minutes }\end{array}$ & & $\begin{array}{l}\text { 1) Continuous } \\
\text { 2) Intermittent }\end{array}$ \\
\hline $\begin{array}{c}\text { Xie F. et al. } \\
\text { [77] } \\
\text { JAm Soc } \\
\text { Echocar- } \\
\text { diogr } 2011\end{array}$ & $\begin{array}{l}\text { Acute } \\
\text { thrombotic } \\
\text { coronary } \\
\text { occlusion } \\
\text { created in } \\
\text { pigs }\end{array}$ & $\begin{array}{l}\text { left anterior } \\
\text { descending coro- } \\
\text { nary artery }\end{array}$ & $\begin{array}{c}\text { Lipid } \\
\text { encapsul. } \\
\text { formulation } \\
\text { (MRX-801) }\end{array}$ & $\begin{array}{l}\text { Guided } \\
\text { diagnos- } \\
\text { tic ultra- } \\
\text { sound }\end{array}$ & $\begin{array}{l}\text { 3D trans- } \\
\text { ducer }\end{array}$ & $1.6 \mathrm{MHz}$ & $\begin{array}{l}\text { High-MI } \\
\text { (1.2) }\end{array}$ & $\begin{array}{l}\text { Total time } \\
=30 \mathrm{~min}\end{array}$ & $\begin{array}{c}5 \mathrm{~Hz} / 5 \mathrm{~s} \\
(25)\end{array}$ & Intermittent \\
\hline $\begin{array}{l}\text { Xie F et } \\
\text { al. [75] } \\
\text { PlosOne } \\
2013\end{array}$ & $\begin{array}{l}\text { Hyperlipid- } \\
\text { emic athero- } \\
\text { sclerotic pigs }\end{array}$ & $\begin{array}{l}\text { Thrombotic } \\
\text { occlusion in } \\
\text { mid-left anterior } \\
\text { descending } \\
\text { artery }\end{array}$ & & $\begin{array}{l}\text { Guided } \\
\text { diagnos- } \\
\text { tic ultra- } \\
\text { sound } \\
\text { Low-MI } \\
\text { con- } \\
\text { trast-on- } \\
\text { ly } \\
\text { imaging } \\
\text { mode } \\
(0.1)\end{array}$ & & $1.6 \mathrm{MHz}$ & $\begin{array}{l}\text { 1) High- } \\
\text { MI (2.0) } \\
\text { 2) High- } \\
\text { MI (1.0) }\end{array}$ & $\begin{array}{l}\text { 1) short } \\
\text { pulse (5 } \\
\mu \text { sec) } \\
\\
\text { 2) long } \\
\text { pulse } \\
(20 \mu \mathrm{sec}) \\
\text { Thera- } \\
\text { peutic ul- } \\
\text { trasound } \\
\text { impulses: } \\
5 \text { sec Total } \\
=30 \text { min }\end{array}$ & $50 \mathrm{~Hz}$ & Intermittent \\
\hline $\begin{array}{c}\text { Mathias } \\
\text { W Jr. et al. } \\
\text { [12] } \\
\text { J Am Coll } \\
\text { Cardiol } \\
2016\end{array}$ & $\begin{array}{l}\text { Patients with } \\
\text { first acute } \\
\text { ST-segment } \\
\text { elevation } \\
\text { myocardial } \\
\text { infarction } \\
\text { divided in } 4 \\
\text { groups }\end{array}$ & $\begin{array}{l}\text { Majority: left an- } \\
\text { terior descending } \\
\text { coronary artery } \\
\text { and left circum- } \\
\text { flex coronary } \\
\text { artery }\end{array}$ & $\begin{array}{l}\text { Perflutren } \\
\text { lipid micro- } \\
\text { sphere (5\% } \\
\text { Definity) }\end{array}$ & $\begin{array}{l}\text { Guided } \\
\text { diagnos- } \\
\text { tic ultra- } \\
\text { sound }\end{array}$ & & $\begin{array}{l}\text { 1) } 1.8 \\
\mathrm{MHz} \\
\text { 2) } 1.3 \\
\mathrm{MHz} \\
\text { 3) } 1.8 \\
\mathrm{MHz} \\
\text { 4) } 1.8 \\
\mathrm{MHz} \\
\text { Intervals } \\
\text { between } \\
\mathrm{HMI} \\
\text { impulses } \\
\text { varie } \\
\text { from } 5 \text { to } \\
15 \mathrm{~s}\end{array}$ & $\begin{array}{l}\text { 1) High- } \\
\text { MI (1.1 } \\
\text { 1.3) } \\
\text { 2) High- } \\
\text { MI (1.3) } \\
\\
\text { 3) High- } \\
\text { MI (1.3) } \\
\text { 4) Low- } \\
\text { MI (0.18) }\end{array}$ & $\begin{array}{c}\text { 1) short- } \\
\text { pulse } 3 \mu \mathrm{s} \\
\text { 2) long- } \\
\text { pulse } 5 \mu \mathrm{s} \\
\text { 3) long } \\
\text { pulse } 20 \\
\mu \mathrm{s} \\
\text { 4) short- } \\
\text { pulse } 3 \mu \mathrm{s} \\
\text { Total time } \\
\text { for all } \\
\text { groups } \cong \\
1 \mathrm{~h}\end{array}$ & $\begin{array}{l}\text { 1) } 25 \mathrm{~Hz} \\
\text { 2) } 10 \mathrm{~Hz} \\
\text { 3) } 5 \mathrm{~Hz} \\
\text { 4) } 25 \mathrm{~Hz}\end{array}$ & $\begin{array}{l}\text { Intermittent for } \\
\text { all groups }\end{array}$ \\
\hline
\end{tabular}




\begin{tabular}{|c|c|c|c|c|c|c|c|c|c|c|}
\hline $\begin{array}{l}\text { Roos ST et } \\
\text { al. [82] } \\
\text { Ultrasound } \\
\text { in Med. \& } \\
\text { Biol. } 2016\end{array}$ & $\begin{array}{l}\text { ST-segment } \\
\text { elevation } \\
\text { myocardial } \\
\text { infarction } \\
\text { patients. }\end{array}$ & $\begin{array}{l}\text { Right coronary } \\
\text { artery, left ante- } \\
\text { rior descending } \\
\text { and circumflex } \\
\text { artery myocardial } \\
\quad \text { infarctions }\end{array}$ & $\begin{array}{l}\text { Definity mi- } \\
\text { crospheres }\end{array}$ & $\begin{array}{l}\text { Guided } \\
\text { diagnos- } \\
\text { tic ultra- } \\
\text { sound }\end{array}$ & S5-1 & $1.6 \mathrm{MHz}$ & $\begin{array}{l}\text { High-MI } \\
(1.3)\end{array}$ & $\begin{array}{l}\text { long-pulse } \\
20 \mu \mathrm{s} \\
\text { Diagnostic } \\
\text { US and } \\
\text { thera- } \\
\text { peutic } \\
\text { US were } \\
\text { alternated } \\
\text { at the rate } \\
\text { of } 15 \mathrm{~s} \text { per } \\
\text { imaging } \\
\text { mode }\end{array}$ & $50 \mathrm{~Hz}$ & Intermittent \\
\hline $\begin{array}{l}\text { Mathias } \\
\text { W Jr. et al. } \\
\text { [13] J Am } \\
\text { Coll Cardiol } \\
2019\end{array}$ & $\begin{array}{l}\text { Patients with } \\
\text { first acute } \\
\text { ST-segment } \\
\text { elevation } \\
\text { myocardial } \\
\text { infarction } \\
\text { divided in } 2 \\
\text { groups }\end{array}$ & & $\begin{array}{l}\text { Perflutren } \\
\text { lipid micro- } \\
\text { sphere (5\% } \\
\text { Definity) }\end{array}$ & $\begin{array}{l}\text { Guided } \\
\text { diagnos- } \\
\text { tic ultra- } \\
\text { sound }\end{array}$ & & $\begin{array}{l}\text { 1) } 1.8 \\
\text { MHz } \\
\text { short- } \\
\text { pulse } \\
\text { 2) } 1.8 \\
\text { MHz LMI } \\
\text { + PCI }\end{array}$ & $\begin{array}{l}\text { 1) High- } \\
\text { MI (1.1- } \\
1.3) \\
\text { 2) Low- } \\
\text { MI (0.18) }\end{array}$ & $\begin{array}{c}1)<5 \\
\mu \mathrm{sec} \\
\text { Total time } \\
\cong 50 \mathrm{~min} \\
\\
\text { High-MI } \\
\text { impulses } \\
\text { applied } \\
\text { for } 10 \mathrm{sec} \\
\text { intervals } \\
\text { repeatedly }\end{array}$ & 1) $25 \mathrm{~Hz}$ & Intermittent \\
\hline
\end{tabular}

Note: $\mathrm{MI}=$ Mechanical Index

Thus, microbubbles or their daughters survive as clusters that persist and continue to oscillate with large amplitude. Inertial cavitation dose, as a measure of therapeutic potential, increased with acoustic pressure and microbubbles concentration. The authors suggested that for therapies such as sonothrombolysis within the inertial cavitation regime, long pulses with durations of 100 cycles $(0.1 \mathrm{~ms})$ or longer could be used to harvest the therapeutic effect conferred by remnant bubbles as cavitation nuclei to sustain cavitation activity. Wu et al. [81] also regarding the US pulse duration tested, using an in vitro model flow system with occlusive porcine arterial thrombi, the effect of 10-min treatments with two different pulse duration (5 and $20 \mu \mathrm{s}$ ) using a transducer (1.6-MHz center frequency) at a range of MIs (from 0.2 to 1.4 ) and intermittent impulses delivery to permit microbubble replenishment within the thrombosed vessel.

Percentage thrombus dissolution was significantly higher with $20-\mu$ s pulse duration already at the 0.2 and 0.4 MI therapeutic impulses. At higher MI settings and 20 - $\mu$ s pulse duration, percentage thrombus dissolution decreased most likely from high-intensity cavitation shielding of the thrombus. Important to highlight that the pulse duration prolonging on a diagnostic transducer caused improved sonothrombolysis at a lower mechanical index. In animal model, Xie et al. [75] compared short pulse duration (5 $\mu \mathrm{sec})$ versus long pulse duration $(20 \mu \mathrm{sec})$ to treat thrombotic occlusion of pig coronary artery and concluded that although short pulse duration guided therapeutic impulses from a diagnostic transducer transiently improved microvascular flow, long pulse duration produced sustained epicardial and microvascular reflow in acute myocardial infarction. Despite results of potentiated sonothrombolysis with longer pulse duration, the studies in humans present different findings. First, Mathias et al. [12] found an effective sonothrombolysis response to treat STEMI patients using short pulse ( $3 \mu \mathrm{s}$ ) compared with longer pulse durations (5 $20 \mu \mathrm{s})$, both applied with high-MI (1.1-1.3).
Of importance is the fact that unexpected high incidence of coronary vasoconstriction was observed using sonolysis of long pulse duration and high-MI to treat STEMI patients [82]. This trial (ROMIUS) was aborted after inclusion of 6 patients because three patients experienced coronary vasoconstriction distal to the culprit artery who were unresponsive to nitroglycerin. Thus, the biosafety for the treatment of coronary thrombose applying long pulse duration is still controversy despite the improved microvascular recovery.

Related to the desired MI to enhance microbubbles cavitation and produce thrombolysis, it is already known thelinear relationship between the peak negative pressure $(\mathrm{kPa})$ and mechanical indexes. As higher peak negative pressure leads to higher microbubbles cavitation, Xie F. et al. [39] tested whether intermittent high-MI impulses from diagnostic US could dissolve intravascular thrombi using intravenous microbubbles in a canine model. For that, they recorded cavitational activity all the way down from 2.0 to $0.5 \mathrm{MI}$ and observed a fall when an MI of $<0.5$ was applied. The authors concluded that intravascular cavitational activity occurs within a deeply located thrombosed vessel when high-MI impulses were applied after the replenishment of the insonified field with microbubbles. The angiographic success rate with intermittent high-MI US was of $79 \%$ at 45 min, compared with $30 \%$ at this time in the low-MI US alone. More importantly, they showed that a diagnostic transducer has the capability of simultaneously being both the guiding transducer (at a low-MI) and the therapeutic transducer (brief 1.9-MI impulses).

As a final point, intermittent therapeutic US mode will be preferred considering that studies applying therapeutic US in an uninterrupted fashion, [83,84] may have reduced the effectiveness of the microbubbles by prohibiting replenishment of microbubbles within the field of interest that would serve as nuclei for the desired cavitation effect. Considering the results of the studies and although 
knowing that modification of some characteristics of US and even of the microbubbles may potentiate the effect of sonotrombolysis we must keep in mind that undesirable bio-effects should be avoided in the treatment of patients. It seems that additional studies may still bring relevant information to find the ideal pulse duration or MI or other characteristic in order to maximize the bio-effects without causing serious harm to the patient.

\section{References}

1. Lew AS, Hod H, Cercek B, Shah PK, Ganz W (1987) Mortality and morbidity rates of patients older and younger than 75 years with acute myocardial infarction treated with intravenous streptokinase. Am J Cardiol 59(1): 1-5.

2. Gore JM, Sloan M, Price TR, Randall AM, Bovill E (1991) Intracerebral hemorrhage, cerebral infarction, and subdural hematoma after acute myocardial infarction and thrombolytic therapy in the Thrombolysis in Myocardial Infarction Study. Thrombolysis in Myocardial Infarction, Phase II, pilot and clinical trial. Circulation 83(2): 448-459.

3. Shifrin EG, Anner H, Levy P, Milgalter E (1985) Arterio-venous fistula in the lower limb in consequence of Fogarty balloon catheter embolectomy. Case report and review of the literature. J Cardiovasc Surg (Torino) 26(3): 310-313.

4. Trubestein G, Engel C, Etzel F, Sobbe A, Cremer H, et al. (1976) Thrombolysis by ultrasound. Clin Sci Mol Med Suppl 3: 697s-698s.

5. Trubestein G (1978) Removal of intravascular thrombi by means of ultrasonics. Experimental study with a new method and its clinical use. Fortschr Med 96(14): 755-760.

6. Hong AS, Chae JS, Dubin SB, Lee S, Fishbein MC, et al. (1990) Ultrasonic clot disruption: an in vitro study. Am Heart J 120(2): 418-422.

7. Ariani M, Fishbein MC, Chae JS, Sadeghi H, Michael AD (1991) Dissolution of peripheral arterial thrombi by ultrasound. Circulation 84(4): 16801688.

8. Rosenschein U, Bernstein JJ, DiSegni E, Kaplinsky E, Bernheim J (1990) Experimental ultrasonic angioplasty: disruption of atherosclerotic plaques and thrombi in vitro and arterial recanalization in vivo. J Am Coll Cardiol 15(3): 711-717.

9. Steffen W, Fishbein MC, Luo H, Lee DY, Nita H (1994) High intensity, low frequency catheter-delivered ultrasound dissolution of occlusive coronary artery thrombi: an in vitro and in vivo study. J Am Coll Cardiol 24(6): 1571-1579.

10. Siegel RJ, Don Michael TA, Fishbein MC, Bookstein J, Adler L (1990) In vivo ultrasound arterial recanalization of atherosclerotic total occlusions. J Am Coll Cardiol 15(2): 345-351.

11. Rosenschein U, Roth A, Rassin T, Basan S, Laniado S (1997) Analysis of coronary ultrasound thrombolysis endpoints in acute myocardial infarction (ACUTE trial). Results of the feasibility phase. Circulation 95(6): 1411-1416.

12. Mathias W, Tsutsui JM, Tavares BG, Xie F, Aguiar MO (2016) Diagnostic Ultrasound Impulses Improve Microvascular Flow in Patients with STEMI Receiving Intravenous Microbubbles. J Am Coll Cardiol 67(21): 2506-2515.

13. Mathias W, Tsutsui JM, Tavares BG, Fava AM, Aguiar MOD, et al. (2019) Sonothrombolysis in ST-segment Elevation Myocardial Infarction Treated with Primary Percutaneous Coronary Intervention. J Am Coll Cardiol 73(22): 2832-2842.

14. Hamm CW, Reimers J, Koster R, Terres W, Stiel GM (1994) Coronary ultrasound thrombolysis in a patient with acute myocardial infarction. Lancet 343(1): 605-606.

15. Siegel RJ, Cumberland DC, Myler RK, DonMichael TA (1989) Percutaneous ultrasonic angioplasty:initial clinical experience. Lancet 2: 772-774.
16. Rosenschein U, Rozenszajn LA, Kraus L, Marboe CC, Watkins JF (1991) Ultrasonic angioplasty in totally occluded peripheral arteries. Initial clinical, histological, and angiographic results. Circulation 83(6): 19761986.

17. Siegel RJ, Gaines P, Crew JR, Cumberland DC (1993) Clinical trial of percutaneous peripheral ultrasound angioplasty. J Am Coll Cardiol 22(2): 480-488.

18. Steffen W, Bertrand ME, Hamm CW, de Scheerder I, Lablanche JM (1995) C. Multicenter Experience with Therapeutic Ultrasound Coronary Angioplasty in Symptomatic Patients. Circulation Supplement I 92: 1570.

19. Siegel RJ, Gunn J, Ahsan A, Fishbein MC, Bowes RJ, et al. (1994) Use of therapeutic ultrasound in percutaneous coronary angioplasty. Experimental in vitro studies and initial clinical experience. Circulation 89: 1587-1592.

20. Hamm CW, Steffen W, Terres W, de Scheerder I, Reimers J (1997) Intravascular therapeutic ultrasound thrombolysis in acute myocardial infarctions. Am J Cardiol 80(2): 200-204.

21. Hamm CW, Steffen W, Reimers J, Terres W (1995) Ultrasound Induced Thrombolysis in Patients with Acute Myocardial Infarctions. Circulation Supplement I p. 92.

22. Tachibana K (1992) Enhancement of fibrinolysis with ultrasound energy. J Vasc Interv Radiol 3(2): 299-303.

23. Lauer CG, Burge R, Tang DB, Bass BG, Gomez ER (1992) Effect of ultrasound on tissue-type plasminogen activator-induced thrombolysis. Circulation 86(4): 1257-1264.

24. https://www.ncbi.nlm.nih.gov/pubmed/8498294

25. Kudo S (1989) Thrombolysis with ultrasound effect. Tokyo Jikeikai Med J 104: 1005-1112.

26. Tachibana K, Tachibana S (1995) Albumin microbubble echo-contrast material as an enhancer for ultrasound accelerated thrombolysis. Circulation 92(5): 1148-1150.

27. Porter TR (2009) The utilization of ultrasound and microbubbles for therapy in acute coronary syndromes. Cardiovasc Res 83(4): 636-642.

28. Philippe F, Drobinski G, Bucherer C, Ankri A, Lacombe C (1993) Effects of ultrasound energy on thrombi in vitro. Cathet Cardiovasc Diagn 28(2): 173-178.

29. Rosenschein U, Frimerman A, Laniado S, Miller HI (1994) Study of the mechanism of ultrasound angioplasty from human thrombi and bovine aorta. Am J Cardiol 74(12): 1263-1266

30. Porter TR, LeVeen RF, Fox R, Kricsfeld A, Xie F (1996) Thrombolytic enhancement with perfluorocarbon-exposed sonicated dextrose albumin microbubbles. Am Heart J 132(5): 964-968.

31. Luo H, Nishioka T, Fishbein MC, Cercek B, Forrester JS (1996) Transcutaneous ultrasound augments lysis of arterial thrombi in vivo. Circulation 94(4): 775-778.

32. Steffen W, Siegel RJ (1993) Ultrasound angioplasty--a review. J Interv Cardiol 6(1): 77-88.

33. Kornowski R, Meltzer RS, Chernine A, Vered Z, Battler A (1994) Does external ultrasound accelerate thrombolysis? Results from a rabbit model. Circulation 89(1): 339-344.

34. Blinc A, Francis CW, Trudnowski JL, Carstensen EL (1993) Characterization of ultrasound-potentiated fibrinolysis in vitro. Blood 81(10): 2636-2643.

35. Siegel RJ (1995) Ultrasound Angioplasty. In Siegel RJ (Eds.), Kluwer Academic Publishers, 1995.

36. Goldman DE, Lepeschkin WW (1952) Injury to living cells in standing sound waves. J Cell Comp Physiol 40(2): 255-268.

37. Phenix CP, Togtema M, Pichardo S, Zehbe I, Curiel L (2014) High intensity focused ultrasound technology, its scope and applications in therapy and drug delivery. J Pharm Pharm Sci 17(1): 136-153. 
38. Chen X, Leeman JE, Wang J, Pacella JJ, Villanueva FS (2014) New insights into mechanisms of sonothrombolysis using ultra-high-speed imaging. Ultrasound Med Biol 40(1): 258-262.

39. Xie F, Lof J, Everbach C, He A, Bennett RM (2009) Treatment of acute intravascular thrombi with diagnostic ultrasound and intravenous microbubbles. JACC Cardiovasc Imaging 2(4): 511-518.

40. Siegel RJ, Suchkova VN, Miyamoto T, Luo H, Baggs RB, et al. (2004) Ultrasound energy improves myocardial perfusion in the presence of coronary occlusion. J Am Coll Cardiol 44(7): 1454-1458.

41. Belcik JT, Mott BH, Xie A, Zhao Y, Kim S, et al. (2015) Augmentation of limb perfusion and reversal of tissue ischemia produced by ultrasoundmediated microbubble cavitation. Circ Cardiovasc Imaging 8(4).

42. Leone AM, D’Amario D, Teofili L, Basile E, Cannata F, et al. (2016) The combined effect of subcutaneous granulocyte- colony stimulating factor and myocardial contrast echocardiography with intravenous infusion of sulfur hexafluoride on post-infarction left ventricular function, the RIGENERA 2.0 trial: study protocol for a randomized controlled trial. Trials 17: 97.

43. Loffredo FS, Steinhauser ML, Gannon J, Lee RT (2011) Bone marrowderived cell therapy stimulates endogenous cardiomyocyte progenitors and promotes cardiac repair. Cell Stem Cell 8(4): 389-398.

44. Arnous S, Mozid A, Martin J, Mathur A (2012) Bone marrow mononuclear cells and acute myocardial infarction. Stem Cell Res Ther 3(1): 2.

45. Xu YL, Gao YH, Liu Z, Tan KB, Hua X, et al. (2010) Myocardium-targeted transplantation of mesenchymal stem cells by diagnostic ultrasoundmediated microbubble destruction improves cardiac function in myocardial infarction of New Zealand rabbits. Int J Cardiol 138(2): 182195.

46. Ghanem A, Steingen C, Brenig F, Funcke F, Bai ZY, et al. (2009) Focused ultrasound-induced stimulation of microbubbles augments sitetargeted engraftment of mesenchymal stem cells after acute myocardial infarction. J Mol Cell Cardiol 47(3): 411-418.

47. Miyamoto T, Neuman Y, Luo H, Jeon DS, Kobal S, et al. (2003) Coronary vasodilation by noninvasive transcutaneous ultrasound: an in vivo canine study. J Am Coll Cardiol 41(9): 1623-1627.

48. Iida K, Luo H, Hagisawa K, Akima T, Shah PK, et al. (2006) Noninvasive low-frequency ultrasound energy causes vasodilation in humans. J Am Coll Cardiol 48(3): 532-537.

49. Lindner JR (2004) Microbubbles in medical imaging: current applications and future directions. Nat Rev Drug Discov 3(6): 527-532.

50. Lindner JR, Song J, Jayaweera AR, Sklenar J, Kaul S (2002) Microvascular rheology of Definity microbubbles after intra-arterial and intravenous administration. J Am Soc Echocardiogr 15(5): 396-403.

51. Wei K, Jayaweera AR, Firoozan S, Linka A, Skyba DM (1998) Quantification of myocardial blood flow with ultrasound-induced destruction of microbubbles administered as a constant venous infusion. Circulation 97: 473-483.

52. Lepper W, Belcik T, Wei K, Lindner JR, Sklenar J (2004) Myocardial contrast echocardiography. Circulation 109: 3132-3135.

53. Cooper MJ, Bernstein D, Silverman NH (1985) Recognition of left coronary artery fistula to the left and right ventricles by contrast echocardiography. J Am Coll Cardiol 6(4): 923-926.

54. Klibanov AL (1999) Targeted delivery of gas-filled microspheres, contrast agents for ultrasound imaging. Adv Drug Deliv Rev 37(1-3): 139-157.

55. Wheatley MA, Schrope B, Shen P (1990) Contrast agents for diagnostic ultrasound: development and evaluation of polymer-coated microbubbles. Biomaterials 11(9): 713-717.

56. Keller MW, Feinstein SB, Watson DD (1987) Successful left ventricular opacification following peripheral venous injection of sonicated contrast agent: an experimental evaluation. Am Heart J 114(3): 570-575.
57. Unger EC, Lund PJ, Shen DK, Fritz TA, Yellowhair D (1992) Nitrogenfilled liposomes as a vascular US contrast agent: preliminary evaluation. Radiology 185(2): 453-456.

58. Shapiro JR, Reisner SA, Amico AF, Kelly PF, Meltzer RS (1990) Reproducibility of quantitative myocardial contrast echocardiography. J Am Coll Cardiol 15(3): 602-609.

59. Chomas JE, Dayton P, Allen J, Morgan K, Ferrara KW (2001) Mechanisms of contrast agent destruction. IEEE Trans Ultrason Ferroelectr Freq Control 48(1): 232-248.

60. de Jong N, Hoff L, Skotland T, Bom N (1992) Absorption and scatter of encapsulated gas filled microspheres: theoretical considerations and some measurements. Ultrasonics 30(2): 95-103.

61. Medwin H (1977) Counting bubbles acoustically: a review. Ultrasonics 15(1): 7-13.

62. Leong-Poi H, Song J, Rim SJ, Christiansen J, Kaul S (2002) Influence of microbubble shell properties on ultrasound signal: Implications for lowpower perfusion imaging. J Am Soc Echocardiogr 15(10): 1269-1276.

63. Skyba DM, Camarano G, Goodman NC, Price RJ, Skalak TC (1996) Hemodynamic characteristics, myocardial kinetics and microvascular rheology of FS-069, a second-generation echocardiographic contrast agent capable of producing myocardial opacification from a venous injection. J Am Coll Cardiol 28(5): 1292-1300.

64. Mizushige K, Kondo I, Ohmori K, Hirao K, Matsuo H (1999) Enhancement of ultrasound-accelerated thrombolysis by echo contrast agents: dependence on microbubble structure. Ultrasound Med Biol 25(9): 1431-1437.

65. Nishioka T, Luo H, Fishbein MC, Cercek B, Forrester JS (1997) Dissolution of thrombotic arterial occlusion by high intensity, low frequency ultrasound and dodecafluoropentane emulsion: an in vitro and in vivo study. J Am Coll Cardiol 30(2): 561-568.

66. Porter TR, Mulvagh SL, Abdelmoneim SS, Becher H, Belcik JT, et al. (2018) Clinical Applications of Ultrasonic Enhancing Agents in Echocardiography: 2018 American Society of Echocardiography Guidelines Update. J Am Soc Echocardiogr 31(3): 241-274.

67. Tsutsui JM, Kusler M, Porter TR (2005) Intravenous myocardial contrast echocardiography for the diagnosis of coronary artery disease. Curr Opin Cardiol 20(5): 381-385.

68. Porter TR, D’Sa A, Turner C, Jones LA, Minisi AJ, et al. (1993) Myocardial contrast echocardiography for the assessment of coronary blood flow reserve: validation in humans. J Am Coll Cardiol 21(2): 349-355.

69. Pathan F, Marwick TH (2015) Myocardial perfusion imaging using contrast echocardiography. Prog Cardiovasc Dis 57(6): 632-643.

70. Kaul S, Jayaweera AR (1993) Myocardial contrast echocardiography has the potential for the assessment of coronary microvascular reserve. J Am Coll Cardiol 21(2): 356-358.

71. Lindner JR, Wei K (2002) Contrast echocardiography. Curr Probl Cardiol 27: 454-519.

72. Hayat SA, Senior R (2008) Myocardial contrast echocardiography in ST elevation myocardial infarction: ready for prime time? Eur Heart J 29(3): 299-314.

73. Chelliah R, Senior R (2009) An update on contrast echocardiography. Minerva Cardioangiol 57(4): 483-93.

74. Porter TR, Li S, Oster R, Deligonul U (1998) The clinical implications of no reflow demonstrated with intravenous perfluorocarbon containing microbubbles following restoration of Thrombolysis In Myocardial Infarction (TIMI) 3 flow in patients with acute myocardial infarction. Am J Cardiol 82(10): 1173-1177.

75. Xie F, Gao S, Wu J, Lof J, Radio S, et al. (2013) Diagnostic ultrasound induced inertial cavitation to non-invasively restore coronary and microvascular flow in acute myocardial infarction. PLoS One 8(7): e69780. 
76. Miller DL, Driscoll EM, Dou C, Armstrong WF, Lucchesi BR (2006) Microvascular permeabilization and cardiomyocyte injury provoked by myocardial contrast echocardiography in a canine model. J Am Coll Cardiol 47(7): 1464-1468.

77. Xie F, Slikkerveer J, Gao S, Lof J, Kamp 0, et al. (2011) Coronary and microvascular thrombolysis with guided diagnostic ultrasound and microbubbles in acute ST segment elevation myocardial infarction. J Am Soc Echocardiogr 24(12): 1400-1408.

78. Mathias W, Arrieta SR, Tavares GMP, Sbano JCN, Tsutsui JM (2019) Successful Recanalization of Thrombotic Occlusion in Pulmonary Artery Stent Using Sonothrombolysis. CASE (Phila) 3(1): 14-17.

79. Bacon DR, Carstensen EL (1990) Increased heating by diagnostic ultrasound due to nonlinear propagation. J Acoust Soc Am 88(1): 26-34.

80. Leeman JE, Kim JS, Yu FT, Chen X, Kim K (2012) Effect of acoustic conditions on microbubble-mediated microvascular sonothrombolysis. Ultrasound Med Biol 38(9): 1589-1598.

\section{ISSN: 2574-1241}

DOI: 10.26717/BJSTR.2019.21.003600

Wilson Mathias Jr. Biomed J Sci \& Tech Res

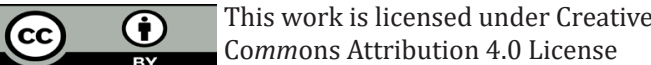

Submission Link: https://biomedres.us/submit-manuscript.php
81. Wu J, Xie F, Kumar T, Liu J, Lof J (2014) Improved sonothrombolysis from a modified diagnostic transducer delivering impulses containing a longer pulse duration. Ultrasound Med Biol 40(7): 1545-1553.

82. Roos ST, Juffermans LJ, van Royen N, van Rossum AC, Xie F (2016) Unexpected High Incidence of Coronary Vasoconstriction in the Reduction of Microvascular Injury Using Sonolysis (ROMIUS) Trial. Ultrasound Med Biol 42(8): 1919-1928.

83. Molina CA, Ribo M, Rubiera M, Montaner J, Santamarina E, et al. (2006) Microbubble administration accelerates clot lysis during continuous $2-\mathrm{MHz}$ ultrasound monitoring in stroke patients treated with intravenous tissue plasminogen activator. Stroke 37(2): 425-429.

84. Pagola J, Ribo M, Alvarez-Sabin J, Lange M, Rubiera M (2007) Timing of recanalization after microbubble-enhanced intravenous thrombolysis in basilar artery occlusion. Stroke 38(11): 2931-2934.

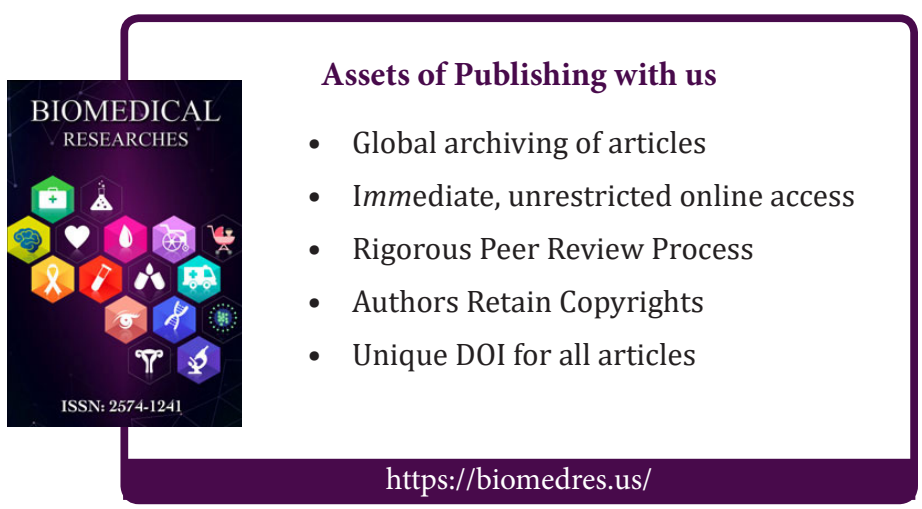

